Bedaquiline is much more widely available than delamanid for adults under programmatic conditions but nearly totally restricted from children due to lack of data [10]. Children with MDR-TB urgently need better treatment options. Expedited enrollment in Janssen's paediatric study of bedaquiline and the availability of the paediatric formulation for the IMPAACT network for its planned study of bedaquiline, including in HIV-positive children, would greatly advance treatment for paediatric MDR-TB. Children affected by MDR-TB, and those who care for them, have already waited too long.

@ERSpublications

Paediatric study of bedaquiline is open but several years behind schedule, delaying access for children with MDR-TB http://ow.ly/4mP8wm

Lindsay McKenna ${ }^{1}$ and Laia Ruiz Mingote ${ }^{2}$

${ }^{1}$ Treatment Action Group, New York, NY, USA. ${ }^{2}$ Global TB Community Advisory Board, Barcelona, Spain.

Correspondence: Lindsay McKenna, Treatment Action Group, 261 Fifth Avenue, Suite 2110, New York, NY 10016, USA. E-mail: Lindsay.McKenna@treatmentactiongroup.org

Received: Feb 192016 | Accepted after revision: April 092016

Conflict of interest: Disclosures can be found alongside the online version of this article at erj.ersjournals.com

\title{
References
}

1 Pontali E, Sotgiu G, D'Ambrosio L, et al. Bedaquiline and multidrug-resistant tuberculosis: a systematic and critical analysis of the evidence. Eur Respir J 2016; 47: 394-402.

2 Jenkins $\mathrm{HE}$, et al. Incidence of multidrug-resistant tuberculosis disease in children: systematic review and global estimates. The Lancet 2014; 383: 1572-1579.

3 World Health Organization. Global Tuberculosis Report 2015. Geneva, World Health Organization, 2015.

4 Nachman S, Ahmed A, Amanullah F, et al. Towards earlier inclusion of children in tuberculosis drug trials: a consensus statement. Lancet Infect Dis 2015; 15: 711-720.

5 Food and Drug Administration. Anti-infective drugs advisory committee meeting briefing document TMC207 (bedaquiline). Treatment of patients with MDR-TB. NDA 204-384. 2012 November 28. www.fda.gov/downloads/ AdvisoryCommittees/CommitteesMeetingMaterials/Drugs/Anti-InfectiveDrugsAdvisoryCommittee/UCM329260.pdf Date last updated: November 28, 2012.

6 McKenna L. Playing catch-up: the pediatric tuberculosis treatment pipeline. www.pipelinereport.org/2014/ pediatric-tb-treatment Date last accessed: February 10, 2016.

7 Global TB Community Advisory Board. Meeting Report: 9th Semiannual Global TB Community Advisory Board Meeting. 30 November 2015; Cape Town, South Africa. www.tbonline.info/media/uploads/documents/tb_cab_ meeting report_december2015 capetown external final.pdf

8 McKenna L. Momentum in the pediatric tuberculosis treatment pipeline. www.pipelinereport.org/2015/ tb-pediatrics Date last accessed: February 10, 2016.

9 Esposito S, D'Ambrosio L, Tadolini M, et al. ERS/WHO Tuberculosis Consilium assistance with extensively drug-resistant tuberculosis management in a child: case study of compassionate delamanid use. Eur Respir J 2014; 44: 811-815.

10 Médecins Sans Frontières Access Campaign. DR-TB Drugs Under the Microscope: Sources and Prices for Drug-Resistant Tuberculosis Medicines, 4th Edn. Geneva, Medecines Sans Frontieres, March 2016.

\section{New anti-tuberculosis drugs for special populations: a difficult-to-address issue}

\section{From the authors:}

We read with interest correspondence from L. McKenna and L. Ruiz Mingote commenting on the editorial by Pontali et al. [1] "Bedaquiline and multidrug-resistant tuberculosis: a systematic and critical analysis of the evidence". Their core message is the lack of availability of the new anti-tuberculosis (TB) drugs (i.e. bedaquiline and delamanid) for childhood TB. In particular, they advocate for rapid initiation of clinical trials in children after the proof of concept and dose-finding (IIa and IIb, respectively) studies carried out in adults.

Childhood TB, and specifically multidrug-resistant TB (MDR-TB) in this age group, has recently gained international relevance both in terms of numbers and difficult management [2-4]. The complicated bacteriological diagnosis in children is well known, so that often the paediatrician needs to rely on the 
child's history of contact without having a drug susceptibility test to guide the regimen's design. In addition, chest radiography is often difficult to interpret, as are signs and symptoms [5, 6]. Furthermore, the lack of paediatric formulations for some of the drugs needed to treat MDR-TB in children creates an unacceptable "double standard", which needs to be tackled urgently [2].

There are several reasons behind the observed delay in making new drugs for children available. The paediatric population, as well as the elderly and pregnant or breastfeeding women, deserve ad-hoc experimental studies. Due to known (clinical, physiological, pharmacokinetic and pharmacodynamic) differences between adults and children, it is in fact not correct to translate "tout court" the findings obtained in adults to the paediatric population.

Specific clinical trials have to be designed to assess the efficacy, safety and tolerability of the new anti-TB drugs and regimens in special TB patient populations. As such trials are long and expensive, it is always difficult to identify companies or organisations willing to plan and implement them.

L. McKenna and L. Ruiz Mingote comment that a compromise should be found for children; when a drug or a regimen demonstrates its safety and efficacy in phase IIb experimental studies, then rapid translation into clinical practice can be activated [7]. It is, however, important to underline that phase IIa and IIb studies are often based on modest sample sizes and the random error related to the sampling procedures could affect a comprehensive evaluation of the efficacy, safety and tolerability profile of the new experimental drug or regimen.

Clinical and ethical considerations about the possible occurrence of rare and life-threatening adverse events need to be balanced against the potential benefits, taking into account the consequences for a new drug/regimen if something goes wrong (e.g. early retirement of the drug).

The European Respiratory Journal welcomes debate on the use of new drugs, particularly in the paediatric population. As we are facing more and more difficulties in the sustainability of the healthcare systems, even in high income countries (e.g. the UK) $[8,9]$, the discussion between policymakers (who look at the public health aspects) and clinicians (who have the dying child in front of them) is not always easy.

- @ERSpublications

Specific clinical trials are needed to assess efficacy, safety \& tolerability of new anti-TB drugs for childhood TB http://ow.ly/X9wl301VNiR

Giovanni Sotgiu ${ }^{1}$, Emanuele Pontali ${ }^{2}$, Rosella Centis ${ }^{3}$, Lia D’Ambrosio ${ }^{3,4}$ and Giovanni Battista Migliori $\circledast^{3}$

${ }^{1}$ Clinical Epidemiology and Medical Statistics Unit, Dept of Biomedical Sciences - University of Sassari - Research, Medical Education and Professional Development Unit, AOU Sassari, Sassari, Italy. ${ }^{2}$ Dept of Infectious Diseases, Galliera Hospital, Genova, Italy. ${ }^{3}$ WHO Collaborating Centre for TB and Lung Diseases, Fondazione S. Maugeri, Care and Research Institute, Tradate, Italy. ${ }^{4}$ Public Health Consulting Group, Lugano, Switzerland.

Correspondence: Giovanni Battista Migliori, WHO Collaborating Centre for TB and Lung Diseases, Fondazione S. Maugeri, Care and Research Institute, via Roncaccio 16, 21049 Tradate, Italy. E-mail: giovannibattista.migliori@fsm.it

Received: June 292016 | Accepted after revision: June 292016

Conflict of interest: Disclosures can be found alongside this article at erj.ersjournals.com

\section{References}

1 Pontali E, Sotgiu G, D'Ambrosio L, et al. Bedaquiline and multidrug-resistant tuberculosis: a systematic and critical analysis of the evidence. Eur Respir J 2016; 47: 394-402.

2 Dodd PJ, Sismanidis C, Seddon JA. Global burden of drug-resistant tuberculosis in children: a mathematical modelling study. Lancet Infect Dis 2016; in press [DOI: 10.1016/S1473-3099(16)30132-3].

3 Tadolini M, Garcia-Prats AJ, D'Ambrosio L, et al. Compassionate use of new drugs in children and adolescents with multidrug-resistant and extensively drug-resistant tuberculosis: early experiences and challenges. Eur Respir J 2016; 48: 938-943.

4 World Health Organization. Global Tuberculosis Report 2015. (Document WHO/HTM/TB/2015.22). Geneva, World Health Organization, 2015.

5 Ettehad D, Schaaf HS, Seddon JA, et al. Treatment outcomes for children with multidrug-resistant tuberculosis: a systematic review and meta-analysis. Lancet Infect Dis 2012; 12: 449-456.

6 Migliori GB, Manissero D, Sotgiu G. Multidrug-resistant tuberculosis in children can be treated. Lancet Infect Dis 2012; 12: 425-426.

7 Nachman S, Ahmed A, Amanullah F, et al. Towards earlier inclusion of children in tuberculosis drug trials: a consensus statement. Lancet Infect Dis 2015; 15: 711-720.

8 Sotgiu G, Humbert M, Dinh-Xuan AT, et al. Clinical trials: registration and transparency. Eur Respir J 2016; 47: $1342-1344$

9 Sotgiu G, Mauch V, Migliori GB, et al. Evidence-based, agreed-upon health priorities to remedy the tuberculosis patient's economic disaster. Eur Respir J 2014; 43: 1563-1566. 